\title{
ESPACAMENTO ENTRE FILEIRAS E DENSIDADE DE SEMEADURA DO SORGO FORRAGEIRO PARA A REGIÃO NORTE DE MINAS GERAIS
}

\author{
Row spacing and sowing density of forage sorghum in the northern region of Minas Gerais
}

\author{
Carlos Juliano Brant Albuquerque ${ }^{1}$, Renzo Garcia Von Pinho', \\ José Avelino Santos Rodrigues ${ }^{3}$, Renata da Silva Brant ${ }^{4}$
}

\begin{abstract}
RESUMO
Em razão da sua resistência à seca, o sorgo forrageiro na forma de silagem é considerado um dos cultivos mais comuns para a alimentação de ruminantes em propriedades da região Norte de Minas Gerais. Para um melhor manejo cultural do sorgo, objetivou-se, neste trabalho, avaliar três densidades de plantas e três espaçamentos entre fileiras na condição climática do semiárido. Para isso, foram conduzidos experimentos, em dois anos agrícolas. Em cada ano foram instalados experimentos em áreas contíguas, utilizando se, respectivamente, os espaçamentos entre linhas de $50 \mathrm{~cm}, 70 \mathrm{~cm} \mathrm{e} 90 \mathrm{~cm}$. Cada experimento foi conduzido sob o delineamento experimental de blocos casualizados em esquema fatorial 4 x 3, com três repetições, sendo quatro cultivares e três densidades de semeadura. A viabilidade da redução do espaçamento entre fileiras no sorgo forrageiro é dependente da cultivar em função da condição climática. $\mathrm{O}$ aumento da densidade de semeadura proporciona redução na produtividade de matéria seca.
\end{abstract}

Termos para indexação: Sorghum bicolor, semiárido, matéria seca, forragem.

\begin{abstract}
Due to its resistance to drought, forage sorghum used as silage, is one of the most common feeds for ruminants on farms in the northern part of the State of Minas Gerais. The present research evaluated three planting densities and three forms of row spacing to determine their efficiency in the production of mass under the semiarid climatic conditions. Two experiments were conducted in two agricultural years. In each year, the experiments were conducted in contiguous areas using row spacing of 50,70 and $90 \mathrm{~cm}$ and three different plant densities. Each experiment used a random blocks design in a 4 × 3 factorial scheme with three replicates, four cultivars and three sowing densities. The viability of reducing the space between rows was found to be dependent on the characteristics of each cultivar as well as the climatic conditions. Increasing sowing density resulted in a proportional reduction in the production of dry matter.
\end{abstract}

Index terms: Sorghum, semiarid, dry matter, forage.

(Recebido em 17 de junho de 2009 e aprovado em 22 de setembro de 2010)

\section{INTRODUÇÃO}

O norte de Minas Gerais é caracterizado como região de semiárido, em consequência dos baixos índices pluviométricos e da inconstância da distribuição das chuvas. A economia regional sofre grande influência da pecuária, em razão do grande número de propriedades agrícolas nesta atividade.

Em razão da sua resistência à seca, o sorgo forrageiro na forma de silagem é considerado um dos cultivos mais comuns para a alimentação de ruminantes em propriedades da região.

A planta de sorgo é adaptada ao processo de ensilagem, em razão de suas características fenotípicas que facilitam o plantio e a colheita, sendo amplamente utilizada na alimentação de animais, pastejo e na produção de silagem para a terminação de bovinos. Essa espécie mostrou-se viável, principalmente em regiões onde o cultivo e o potencial produtivo da cultura do milho sofrem limitações pluviométricas (Chiesa et al., 2008). De modo geral, as silagens de sorgo apresentam de $85 \%$ a $90 \%$ do valor nutritivo das silagens de milho (Zago, 1992).

A viabilidade técnica para o cultivo do sorgo forrageiro na região norte de Minas Gerais foi inicialmente demonstrada na década de 1970, com produtividades de matéria verde superiores a 58 toneladas por hectare (Coelho, 1983). A planta de sorgo se adapta a uma ampla variação de ambientes e produz razoavelmente bem sob condições desfavoráveis, em relação à maioria dos outros cereais (Magalhães \& Durães, 2003).

Entre as práticas e técnicas empregadas para a obtenção de maior produção de sorgo, a escolha da

\footnotetext{
'Empresa de Pesquisa Agropecuária de Minas Gerais/EPAMIG - Fazenda Experimental de Uberlândia/FEUB - Rodovia BR 050 - Km 63 - Marta Helena Cx. P. 2248 - 38402-019 - Uberlândia, MG - carlosjuliano@epamig.br

2Universidade Federal de Lavras/UFLA - Departamento de Agricultura/DAG - Lavras, MG

${ }^{3}$ Empresa Brasileira de Pesquisa Agropecuária/Embrapa - Centro Nacional de Pesquisa de Milho e Sorgo - Sete Lagoas, MG

${ }^{4}$ Universidade Estadual de Montes Claros/Unimontes - Janaúba, MG
} 
densidade ideal de semeadura e do melhor arranjo de plantas na área está entre as mais importantes. De acordo com Baumhardt \& Howell (2006), a escolha da densidade de semeadura do sorgo varia em função do ciclo da cultivar e das condições de umidade prevalecentes. As menores densidades de semeadura podem propiciar maior eficiência na absorção de nutrientes pela cultura do sorgo, em decorrência da competição das plantas nas linhas de plantio (Rosolem et al., 1993; Pholsen \& Suksri, 2007).

Atualmente, trabalhos considerando a produção e a qualidade de forragem do sorgo em diferentes espaçamentos e densidades de semeadura são escassos.

\section{MATERIAL E MÉTODOS}

Os experimentos foram conduzidos, em dois anos agrícolas, em área experimental da Empresa de Pesquisa Agropecuária de Minas Gerais (Epamig), nos anos agrícolas 2006/07 e 2007/08. A área situa-se a 12 km da cidade de Jaíba, MG, nas coordenadas $15^{\circ} 16^{\prime} 20^{\prime \prime} \mathrm{S}$ e $43^{\circ} 40^{\prime} 23^{\prime}$ 'W, à altitude de $456 \mathrm{~m}$, em um Latossolo Vermelho Eutrófico. Os solos são originados de rochas com altos teores de cálcio e potássio, conferindo alta soma de bases e alta saturação de bases.O clima é tropical alternadamente seco e úmido, de acordo com a classificação de Köppen.

Em cada ano, foram instalados três experimentos em áreas contíguas, adotando-se, respectivamente, os espaçamentos entre linhas de $50 \mathrm{~cm}, 70 \mathrm{~cm}$ e $90 \mathrm{~cm}$. Para cada experimento, foram avaliadas três densidades de semeadura, 100 mil, 140 mil e 180 mil plantas ha ${ }^{-1}$, além de quatro cultivares de sorgo forrageiro.

Cada experimento foi conduzido sob o delineamento experimental de blocos casualizados em esquema fatorial $4 \times 3$, com três repetições, sendo quatro cultivares e três densidades de semeadura. A parcela experimental foi constituída de 4 linhas de $5 \mathrm{~m}$ de comprimento e a área útil foi formada pelas duas linhas centrais.

Para todos os experimentos foram utilizados $350 \mathrm{~kg} \mathrm{ha}^{-1}$ da fórmula $4(\mathrm{~N}): 30\left(\mathrm{P}_{2} \mathrm{O}_{5}\right): 10\left(\mathrm{~K}_{2} \mathrm{O}\right)$ mais $0,5 \%$ de $\mathrm{Zn}$, com base na análise de solo. Realizou-se apenas uma adubação de cobertura com $60 \mathrm{~kg} \mathrm{ha}^{-1} \mathrm{de}_{2} \mathrm{O}$ e $80 \mathrm{~kg} \mathrm{ha}^{-1}$ de N. Para o controle de plantas daninhas, foi utilizado, na pós-emergência, o herbicida Gezaprim ${ }^{\circledR} 500$ (atrazine), na dosagem de 31 ha $^{-1}$ do produto comercial.

As sementes foram colocadas de forma manual, uniformemente em sulcos, tomando-se como base o dobro de plantas necessárias para a obtenção das densidades desejadas. Posteriormente, foi realizado o desbaste, com as plantas apresentando cinco folhas, para atingir a população desejada por metro linear, considerando cada espaçamento entre linhas.

Foram avaliadas as características de produtividade de matéria seca, plantas acamadas e quebradas, fibra em detergente neutro, fibra em detergente ácido e proteína bruta. Os dados obtidos foram submetidos, inicialmente, à análise de variância individual por experimento. Previamente foram realizados os testes de aditividade dos dados, normalidade dos erros e homogeneidade das variâncias. Não havendo nenhuma restrição às pressuposições da análise da variância, foi realizada análise de variância conjunta, envolvendo os três experimentos em cada ano e outra, considerando simultaneamente todos os experimentos conduzidos nos dois anos.

Todas as análises, incluindo o estudo de regressão para a produtividade de grãos em função dos diferentes espaçamentos e densidades, foram realizadas utilizando o programa estatístico SISVAR ${ }^{\circledR}$ (Ferreira, 2000). Os dados referentes à porcentagem de plantas acamadas e quebradas foram submetidos a teste de normalidade (distribuição normal de Poisson) e posterior transformação de dados $[\sqrt{\mathrm{x}}+1]$.

\section{RESULTADOS E DISCUSSÃO}

A produtividade média de matéria seca, considerando, os dois anos agrícolas, foi de 15,83 $\mathrm{t} \mathrm{ha}^{-1}$. Esse valor pode ser considerado bom, em decorrência das limitações hídricas acentuadas em 2007/08 (Figura 1).

Notou-se, no segundo ano agrícola, redução de $40 \%$ na produtividade da matéria seca (Tabela 1). Isso ocorreu, em razão da maior precipitação ocorrida em 2006/07, desde o plantio até a colheita dos experimentos. O cultivo do sorgo no semiárido é afetado por diversos fatores do clima, sendo a baixa precipitação o principal fator limitante para produtividade. Portanto, era previsível que o efeito de anos fosse significativo e influenciasse a produtividade média da matéria seca dos experimentos, visto que as condições climáticas variaram de um ano para outro.

No primeiro ano agrícola, registraram-se precipitações de $520 \mathrm{~mm}$ ao longo do ciclo da cultura. As precipitações durante o ciclo da cultura, no segundo ano agrícola, foram de $150 \mathrm{~mm}$, até os 40 dias após a semeadura. Depois desse período, houve um veranico de 25 dias (período de florescimento das plantas) com precipitações de $95 \mathrm{~mm}$ aos 70 dias após a semeadura. As precipitações reduzidas e mal distribuídas nesse período totalizaram um acumulado de $250 \mathrm{~mm}$ ao longo do ciclo da cultura, valor bem inferior ao do primeiro ano (Figura 1). 


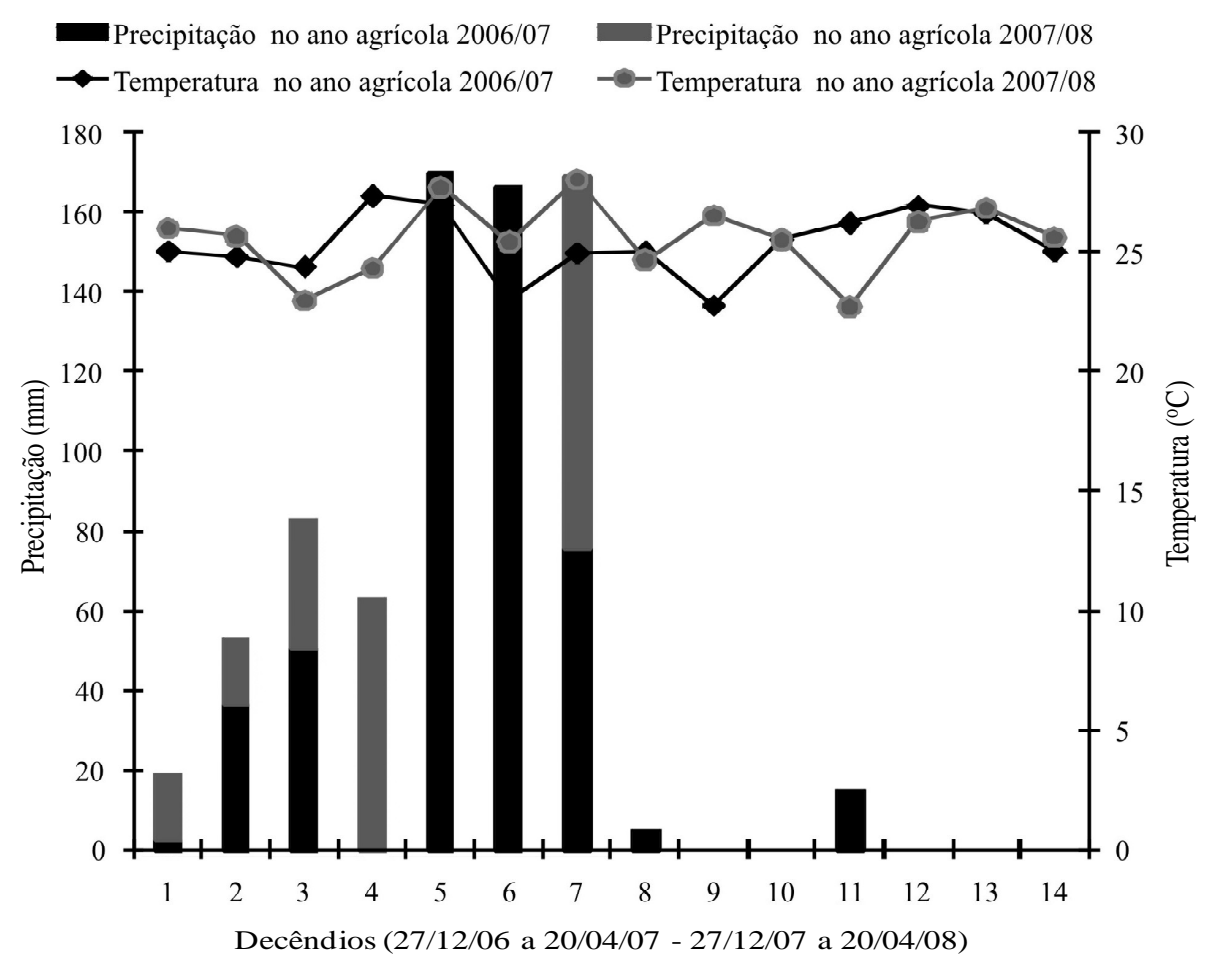

Figura 1 - Dados médios de temperatura e precipitação pluvial por decêndio, em Jaíba, MG, de 27/12/2006 a 20/04/2007 e 27/12/2007 a 20/04/2008. Dados obtidos na estação meteorológica da Epamig em Jaíba, MG.

A ocorrência de déficits hídricos diminui a taxa fotossintética e a multiplicação celular, provocando redução da matéria seca total das plantas (Taiz \& Zeiger, 2004). No presente trabalho, evidenciou-se a grande tolerância da cultura a déficits hídricos, pois foi observada produtividade média de 11,77 t ha ${ }^{-1}$, em 2007/08. O sorgo, por se tratar de uma cultura anual, faz o melhor uso possível dos fatores do meio em curto período de tempo, no qual as condições são favoráveis ao seu desenvolvimento. Nessa situação, quando comparado com o milho, o sorgo consegue produzir mais, em razão do sistema radicular profundo e ramificado, à tolerância a temperaturas elevadas e à capacidade de diminuir o metabolismo e recuperar o desenvolvimento quando o estresse é interrompido (Magalhães \& Durães, 2003).

Foi obtida relação linear significativa para produtividade de matéria seca em função das densidades nos dois anos agrícolas, sendo os coeficientes de determinação $\left(\mathrm{R}^{2}\right)$ de $92,1 \%$, em 2006/07 e 97,8\%, em 2007/08 (Figura 2). Santos et al. (2009) não constataram efeito da densidade na produtividade de matéria do sorgo forrageiro. Entretanto esses autores trabalharam com genótipo com outra base genética.
Tabela 1 - Produtividade de matéria seca $\left(\mathrm{t} \mathrm{ha}^{-1}\right)$, em função dos anos agrícolas e densidades.

\begin{tabular}{|c|c|c|}
\hline \multirow{2}{*}{ Densidades (plantas ha ${ }^{-1}$ ) } & \multicolumn{2}{|c|}{ Anos agrícolas } \\
\hline & $2006 / 07$ & $2007 / 08$ \\
\hline $100 \mathrm{mi}$ & $21,06 \mathrm{aA}$ & $15,52 \mathrm{aB}$ \\
\hline $140 \mathrm{mil}$ & $20,38 \mathrm{aA}$ & $11,19 \mathrm{bB}$ \\
\hline $180 \mathrm{mil}$ & $18,31 \mathrm{bA}$ & $8,62 \mathrm{cB}$ \\
\hline Média & 19,88 & 11,77 \\
\hline
\end{tabular}

Médias com mesma letra minúscula na vertical pertencem ao mesmo agrupamento, de acordo com o teste de Scott-Knott. Na horizontal, médias com a mesma letra maiúscula não diferem entre si, pelo teste de $\mathrm{F}$, a $5 \%$ de probabilidade.

Constatou-se decréscimo de $34 \mathrm{~kg} \mathrm{ha}^{-1} \mathrm{de}$ matéria seca produzida para cada aumento de mil plantas ha ${ }^{-1}$, na safra 2006/07 (Figura 2). Na condição de grande estresse hídrico no experimento conduzido em 2007/08, notou-se que o aumento da densidade acarretou maiores perdas. Para cada aumento de mil plantas ha ${ }^{-1}$, houve um decréscimo de $86 \mathrm{~kg} \mathrm{ha}^{-1}$ de matéria seca (Figura 2). 


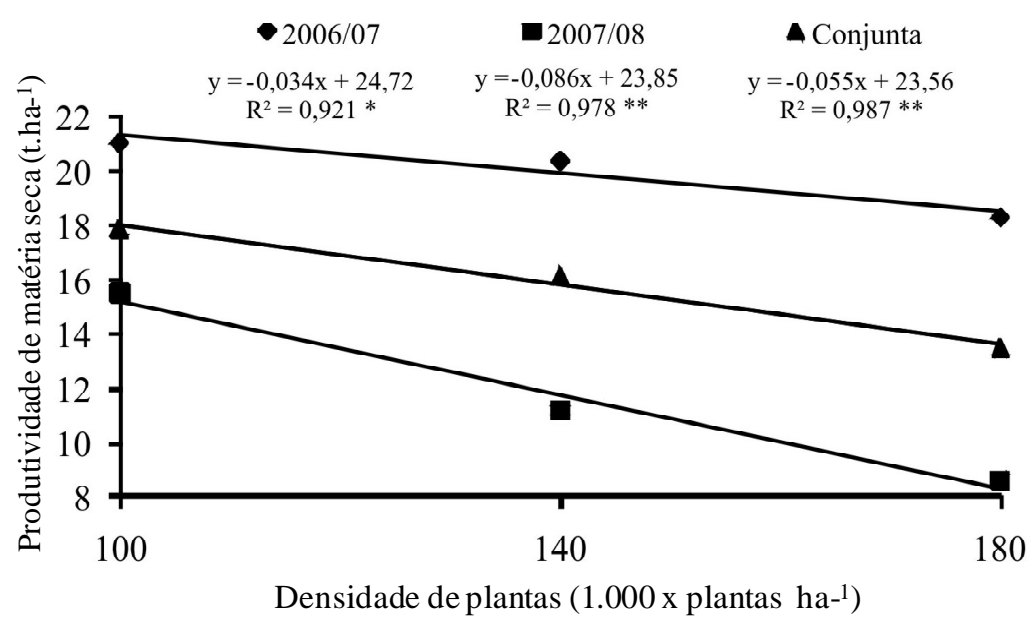

Figura 2 - Representação gráfica das equações de regressão para a produtividade de matéria seca nas densidades, considerando os dois anos de avaliação. *; ** Significativo, a $1 \%$ e a $5 \%$ de probabilidade.

Diante do exposto, pode-se inferir que, em condições de menor disponibilidade hídrica, recomendase a utilização de menores densidades de semeadura, diminuindo a competição entre as plantas na linha de plantio, principalmente por água.

Por se tratar de espécie $\mathrm{C}_{4}$, as altas taxas de luz proporcionam incrementos na produção de matéria seca na cultura do sorgo. Sendo assim, as altas densidades podem ter provocado aumento da competição por luz, água e nutrientes, na linha de semeadura. Em milho, alguns genótipos diminuem a matéria seca de raiz e da parte aérea por unidade de planta com aumento da população (Dourado Neto et al., 2003).

As produtividades de matéria seca foram afetadas pela interação cultivar $x$ anos $x$ espaçamentos $(P \leq 0,01)$. Comparando as cultivares dentro de cada espaçamento, em 2006/07, verificou-se que a cultivar SHS 500 foi mais produtiva que as demais, nos espaçamentos 50, 70 e 90 $\mathrm{cm}$. Nesse ultimo espaçamento, notou-se ainda a cultivar BRS 610 como destaque (Tabela 2). A diminuição da produtividade da cultivar SHS 500 com o aumento do espaçamento de 50 para $90 \mathrm{~cm}$ proporcionou as mesmas produtividades para as duas cultivares.

Os resultados obtidos neste trabalho para maioria das cultivares no primeiro ano agrícola são semelhantes aos encontrados por Pinho et al. (2007) e Santos et al. (2009) na época normal de semeadura na região Sul de Minas Gerais. Esses autores descreveram produtividades entre 17,18 $\mathrm{tha}^{-1}$ a 21,00 $\mathrm{t} \mathrm{ha}{ }^{-1}$ de MS. A exceção foi a cultivar $1 \mathrm{~F} 305$ que apresentou valores menores que os reportados por esses autores.
Não ocorreram diferenças entre as cultivares, dentro de cada espaçamento, na safra 2007/08 (Tabela 2). Isso pode ser creditado ao metabolismo das plantas, que foi afetado pelo estresse hídrico, nesse período. Flaresso et al. (2000) têm recomendado espaçamentos de $70 \mathrm{a} 80 \mathrm{~cm}$ para o cultivo de sorgo forrageiro, como adaptação às colhedeiras utilizadas pela maioria dos produtores. Atualmente, as empresas fabricantes de máquinas agrícolas têm disponibilizado implementos específicos para a colheita de sorgo e de milho semeados em menores espaçamentos, o que poderá aumentar as produtividades dessas culturas.

Foi obtida relação linear significativa para produtividade de matéria seca nos diferentes espaçamentos entre fileiras apenas para cultivar SHS $500 \mathrm{em}$ 2006/07, sendo o coeficiente de determinação superior a $80 \%$ (Figura 3). Notou-se, para cada aumento de um centímetro, decréscimo de $151 \mathrm{~kg} \mathrm{ha}^{-1}$ de matéria seca. Em 2007/08, não foi observada significância para a equação linear.

Esses resultados evidenciam que alguns genótipos são mais afetados pelo aumento do espaçamento. Possivelmente, a composição genética do SHS 500, que lhe confere porte alto e folhas compridas, propiciou a intensificação da competição intraespecífica por luz, principalmente na condição do maior espaçamento, fato que justifica a redução da produtividade deste material.

De acordo com Magalhães \& Durães (2003), à medida que a copa da planta se fecha, outros incrementos no índice de área foliar têm pouco ou nenhum efeito sobre a fotossíntese, a qual passa a depender da radiação solar incidente e da estrutura da copa vegetal. 
Tabela 2 - Resultados médios para produtividade de matéria seca ( $\left.\mathrm{t} \mathrm{ha}^{-1}\right)$ de cultivares de sorgo, em função dos anos agrícolas, espaçamentos e cultivares.

\begin{tabular}{ccccccc}
\hline & \multicolumn{5}{c}{$2006 / 07$} & \multicolumn{3}{c}{ Espaçamentos } \\
\cline { 2 - 6 } Cultivares & $50 \mathrm{~cm}$ & $70 \mathrm{~cm}$ & $90 \mathrm{~cm}$ & $50 \mathrm{~cm}$ & $70 \mathrm{~cm}$ & $90 \mathrm{~cm}$ \\
\cline { 2 - 6 } & $13,04 \mathrm{cA}$ & $10,12 \mathrm{cA}$ & $9,97 \mathrm{cA}$ & $12,11 \mathrm{aA}$ & $15,07 \mathrm{aA}$ & $13,14 \mathrm{aA}$ \\
nyy 305 & $20,53 \mathrm{bA}$ & $17,91 \mathrm{bA}$ & $20,28 \mathrm{aA}$ & $7,15 \mathrm{aA}$ & $10,32 \mathrm{aA}$ & $10,32 \mathrm{aA}$ \\
BRS 610 & $28,66 \mathrm{aA}$ & $23,28 \mathrm{aB}$ & $22,64 \mathrm{aB}$ & $9,98 \mathrm{aA}$ & $11,70 \mathrm{aA}$ & $12,67 \mathrm{aA}$ \\
SHS 500 & $19,23 \mathrm{bA}$ & $17,54 \mathrm{bA}$ & $15,42 \mathrm{bA}$ & $11,97 \mathrm{aA}$ & $13,39 \mathrm{aA}$ & $13,48 \mathrm{aA}$ \\
BRS 655 & &
\end{tabular}

Médias com mesma letra minúscula na vertical e maiúscula na horizontal, dentro de cada espaçamento, pertencem ao mesmo agrupamento, de acordo com o teste de Scott-Knott.

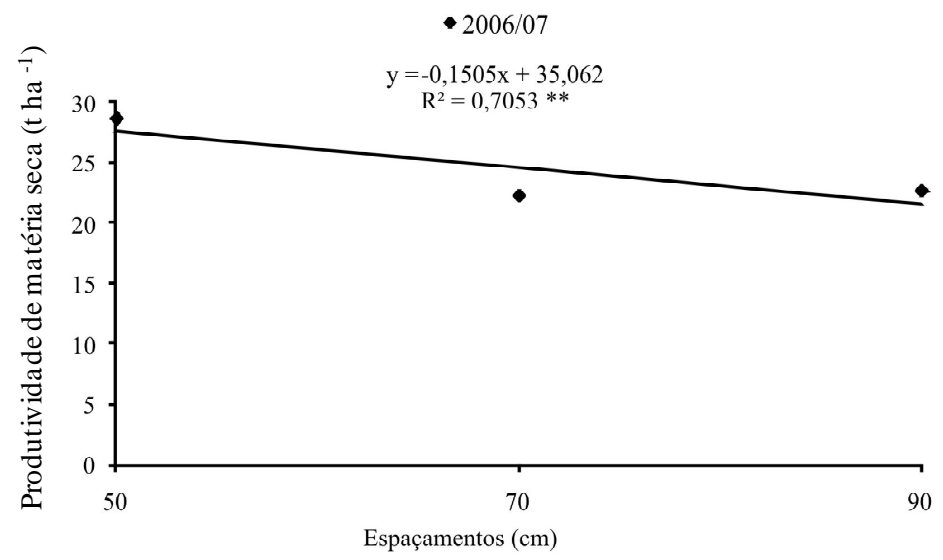

Figura 3 - Representação gráfica das equação de regressão para a produtividade de matéria seca da cultivar SHS 500 nos diferentes espaçamentos em 2006/07. ** Significativo, a $1 \%$ de probabilidade.

Avaliando os espaçamentos entre fileiras de 60, 80 e $100 \mathrm{~cm}$ para o hibrido AG2002, Santos et al. (2009) concluíram que o espaçamento $80 \mathrm{~cm}$ alcançaram maiores rendimentos de matéria seca.

Para porcentagem de proteina bruta, foi obervado efeito significativo para ano agrícola e interação cultivar $\mathrm{x}$ ano. Em 2006/07, registrou-se 8,34\% de proteína bruta, considerando a média de todas as cultivares. No ano posterior, ocorreu redução dos teores de proteína bruta para $7,69 \%$. Esses resultados evidenciam que a melhor distribuição das precipitações em 2006/07 favoreceu o melhor valor nutricional do sorgo. No entanto, apenas a cultivar SHS 500 apresentou redução significativa nos teores de proteína bruta, em 2007/08 (Tabela 3).

Os grupos de cultivares apresentaram comportamento diferenciado nos dois anos de avaliação. No primeiro ano agrícola, não houve diferenças entre as cultivares quanto às porcentagens de proteína bruta.
Tabela 3 - Resultados obtidos para porcentagem de proteína bruta, em função dos anos agrícolas e cultivares. UFLA, Lavras, MG, 2009.

\begin{tabular}{lcc}
\hline Cultivares & \multicolumn{2}{c}{ Proteína bruta } \\
\hline & Ano 2006/07 & Ano 2007/08 \\
\cline { 2 - 3 } 1F305 & $7,68 \mathrm{aA}$ & $7,24 \mathrm{bA}$ \\
BRS 610 & $8,32 \mathrm{aA}$ & $8,17 \mathrm{aA}$ \\
SHS 500 & $8,21 \mathrm{aA}$ & $6,46 \mathrm{bB}$ \\
BRS 655 & $9,16 \mathrm{aA}$ & $8,92 \mathrm{aA}$ \\
\hline
\end{tabular}

Médias com mesma letra minúscula na vertical pertencem ao mesmo agrupamento, de acordo com o teste de Scott-Knott. Na horizontal, médias com a mesma letra maiúscula não diferem entre si, pelo teste de F, a 5\% de probabilidade.

Comparando-se os grupos de cultivares no experimento conduzido em 2007/08, constatam-se, para BRS 655 e BRS 610, maiores porcentagens de proteína bruta. A 
maior porcentagem de panícula na matéria seca nessas cultivares favoreceu o aumento da proteína bruta. Pinho et al. (2007) também verificaram maiores teores de proteína bruta nas cultivares de sorgo com maior proporção de panículas na matéria seca.

Valores diferentes foram constatados por Santos et al. (2009). Esses autores reportaram efeito do espaçamento na proteina bruta da planta inteira do sorgo forrageiro.

Os espaçamentos e as densidades de semeadura não afetaram a porcentagem de proteína bruta das cultivares de sorgo. Para a cultura do milho houve resultados diferentes. Neste trabalho, os espaçamentos afetaram, além do rendimento forrageiro, a qualidade da silagem. No menor espaçamento $(0,50 \mathrm{~m})$ obtiveram-se maior rendimento de espigas, maior rendimento de matéria seca e proteína bruta.

As cultivares avaliadas no ano agrícola 2006/07 apresentaram menores valores de FDN e FDA (Tabela 4). Nesse período, notaram-se valores médios de $54,49 \%$ de FDN e $31,12 \%$ de FDA. Já no segundo ano de experimentação, foram constatados valores de $59,51 \%$ de FDN e 36,14\% de FDA. Resultados semelhantes aos obtidos no segundo ano de experimentação, para FDN, foram evidenciados por Melo et al. (1998) e Resende et al. (2003), com valores entre $60,4 \%$ e $60,98 \%$.

Tabela 4 - Valores médios para porcentagem de fibra em detergente neutro (FDN) e fibra em detergente ácido (FDA) das cultivares de sorgo forrageiro.

\begin{tabular}{ccc}
\hline Cultivares & FDN $(\%)$ & FDA $(\%)$ \\
\hline BRS 655 & $49,96 \mathrm{a}$ & $28,83 \mathrm{a}$ \\
BRS 610 & $55,79 \mathrm{~b}$ & $32,27 \mathrm{~b}$ \\
1 F305 & $59,71 \mathrm{c}$ & $35,06 \mathrm{c}$ \\
SHS 500 & $62,53 \mathrm{~d}$ & $38,37 \mathrm{~d}$ \\
\hline
\end{tabular}

Médias com mesma letra minúscula na vertical pertencem ao mesmo agrupamento, de acordo com o teste de Scott-Knott. Na horizontal, médias com a mesma letra maiúscula não diferem entre si, pelo teste de $\mathrm{F}$, a $5 \%$ de probabilidade.

O teor de FDN é o indicativo de quantidade total de fibra do volumoso, estando diretamente relacionado com o consumo dos animais; a FDA se relaciona com a digestibilidade do volumoso por apresentar maior proporção de lignina na fração digestível (Rosa et al., 2004).

Os menores valores de FDN determinados em 2006/07 foram decorrentes da maior proporção de panículas e menores proporções de colmos e folhas na
MS, relatadas anteriormente, tendo, como consequência, a redução na porcentagem de fibra da forragem. As maiores precipitações relatadas nesse período contribuíram para melhor produção de grãos e, consequentemente, melhor qualidade da forragem.

Alem disso, em 2006/07 as precipitações adequadas favorecem melhor eficiência na absorção de nutrientes, pois os mesmos são absorvidos pelas plantas estando na solução do solo. De acordo com Simili et al. (2008) adubação nitrogenada influencia os teores de proteína bruta do sorgo sudão e a adubação potássica afeta os teores de lignina da planta.

Os valores encontrados para os teores de FDN variaram de $49,96 \%$ a $62,53 \%$ (Tabela 4), estando próximos dos dados reportados por Gontijo Neto et al. (2004). Por outro lado, os teores de FDA oscilaram de 28,83\% a 38,37\% (Tabela 4), estando estes valores acima dos encontrados para outros genótipos de sorgo, por Gontijo Neto et al. (2004), que constataram de $25 \%$ a $31 \%$.

De modo geral, os teores de FDN e FDA foram menores no genótipo BRS 655 e maiores para o SHS 500 (Tabela 4). Os teores de FDN e FDA aqui reportados caracterizam o genótipo BRS 655 como o de melhor qualidade nutricional. Essa cultivar apresentou menor porção de colmo na composição da matéria seca total da planta e maior quantidade de panículas. Com certeza, essa característica foi o principal fator responsável pelos menores teores de FDN e FDA desse material.

As características bromatológicas das forragens não foram influenciadas pelos espaçamentos e densidades adotados. Esses resultados corroboram os obtidos por Alvarez et al. (2006) na cultura do milho submetido a diferentes espaçamentos e densidades de plantas.

\section{CONCLUSÕES}

A redução do espaçamento entre fileiras propicia maior produtividade de matéria seca na cultivar SHS 500, em função das condições climáticas prevalecentes no ano agrícola.

A produtividade de matéria seca das cultivares BRS 655, BRS 610 e 1F305 não são afetadas pela redução do espaçamento entre fileiras.

$\mathrm{O}$ aumento da densidade de semeadura proporciona redução na produtividade de matéria seca.

Os espaçamentos e densidades avaliadas não têm efeito na qualidade da forragem.

Considerando as produtividades de matéria seca, teores de proteína bruta, FDN e FDA, a cultivar BRS 655 é mais indicada para a produção de forragem, independente dos espaçamentos e densidades avaliados. 


\section{AGRADECIMENTOS} financeiro.

Os autores agradecem a FAPEMIG pelo auxílio

\section{REFERÊNCIAS BIBLIOGRÁFICAS}

ALVAREZ, C.G.D.; PINHO, R.G. von; BORGES, I.D. Avaliação de características agronômicas e de produção de forragem e grãos de milho em diferentes densidades de semeadura e espaçamentos entre linhas. Ciência e Agrotecnologia, Lavras, v.30, n.3, p.402-408, maio/jun. 2006.

BAUMHARDT, R.L.; HOWELL, T.A. Seeding practices, cultivar maturity, and irrigation effects on simulated grain sorghum yield. Agronomy Journal, Madison, v.98, n.3, p.462-470, Apr. 2006.

CHIESA, E.D.; ARBOITTE, M.Z.; BRONDANI, I.L.; MENEZES, L.F.G. de; RESTLE, J.; SANTI, M.A.M. Aspectos agronômicos de híbridos de sorgo (Sorghum bicolor L. Moench) no desempenho e economicidade de novilhos confinados. Acta Scientiarum. Animal Sciences, Maringá, v.30, n.1, p.67-73, jan. 2008.

COELHO, A.M. A cultura do sorgo no Norte de Minas: resultados experimentais. Belo Horizonte: Epamig, 1983. (Boletim técnico, 6).

DOURADO NETO, D.; PALHARES, M.; VIEIRA, P.A.; MANFRON, P.A.; MEDEIROS, S.L.P.; ROMANO, M.R. Efeito da população de plantas e do espaçamento sobre a produtividade de milho. Revista Brasileira de Milho e Sorgo, Sete Lagoas, v.2, n.3, p.63-77, set./dez. 2003.

FERREIRA, D.F. Análises estatísticas por meio do SISVAR (Sistema para Análise de Variância) windows 4.0. In: REUNIÃO ANUAL DA REGIÃO BRASILEIRA DA SOCIEDADE INTERNACIONAL DE BIOMETRIA, 45., 2000, São Carlos. Anais... São Carlos: UFSCar, 2000. p.255-258.

FLARESSO, J.A.; GROSS, C.D.; ALMEIDA, E.X. Cultivares de milho (Zea mays L.) e sorgo (Sorghum bicolor (L.) Moench.) para ensilagem no Alto Vale do Itajaí, Santa Catarina. Revista Brasileira de Zootecnia, Viçosa, v.29, n.6, p.1608-1615, nov./dez. 2000.

GONTIJO NETO, M.M.; OBEID, J.A.; PEREIRA, O.G.; CECON, A.C.Q.; ZAGO, C.P.; CANDIDO, M.J.D.; MIRANDA, L.F. Híbridos de sorgo (Sorghum bicolor
(L.) Moench) cultivados sob níveis crescentes de adubação. características agronômicas, carboidratos solúveis e estruturais da planta. Revista Brasileira de Zootecnia, Viçosa, v.33, n.6, p.1975-1984, nov./dez. 2004.

MAGALHÃES, P.C.; DURÃES, F.O.M. Ecofisiologia da produção de sorgo. Sete Lagoas: Embrapa, 2003.

(Comunicado técnico, 87).

MELO, W.M.C.; PINHO, R.G.V.; CARVALHO, M.L.M. Avaliação de cultivares de milho, para produção de silagem na região de Lavras, MG. Ciência e Agrotecnologia, Lavras, v.23, n.1, p.31-39, jan./mar. 1999.

PHOLSEN, S.; SUKSRI, A. Effects of phosphorus and potassium on growth, yield and fodder quality of IS 23585 forage sorghum cultivar (Sorghum bicolor $\mathrm{L}$. Moench). Pakistan Journal of Biological Sciences, v.10, n.10, p.1604-1610, May 2007.

PINHO, R.G.; VASCONCELOS, R.C. de; BORGES, I.D.; RESENDE, A.V. Produtividade e qualidade de silagem de milho e sorgo em função da época de semeadura. Bragantia, Campinas, v.66, n.2, p.235-245, 2007.

RESENDE, J.A.; PEREIRA, M.N.; PINHO, R.G. von; FONSECA, A.H.; SILVA, A.R.P. Ruminal silage degradability and productivity of forage and grain-type sorghum cultivars. Scientia Agricola, Piracicaba, v.60, n.3, p.457-463, 2003.

ROSA, J.R.P.; RESTLE, J.; SILVA, J.H.S. da; PASCOAL, L.L.; PACHECO, P.S.; FATURI, C.; SANTOS, A.P. dos. Avaliação da silagem de diferentes híbridos de milho (Zea mays, L.) por meio do desempenho de bezerros confinados em fase de crescimento. Revita Brasileira de Zootecnia, Viçosa, v.33, n.4, p.1016-1028, jul./ago. 2004.

ROSOLEM, C.A.; KATO, S.M.; MACHADO, J.R.; BICUDO, S.J. Nitrogen redistribution to sorghum grains as affected by plant competition. Plant and Soil, The Hague, v.155/156, n.1, p.199-202, Oct. 1993.

SANTOS, P.J.; REZENDE, P.M.; PASSOS, A.M.A.; CARVALHO, E.A.; CARVALHO, E.V. Consórcio sorgo-soja XIII efeito de sistemas de corte e arranjo de plantas no desempenho forrageiro do sorgo. Ciência e Agrotecnologia, Lavras, v.33, n.2, p.397-404, mar./abr. 2009. 
SIMILI, F.F.; REIS, R.A.; FURLAN, B.N.; PAZ C.C.P.; LIMA, M.L.P.; BELLINGIERI, P.A. Resposta do híbrido de sorgo-sudão à adubação nitrogenada e potássica: composição química e digestibilidade in vitro da matéria orgânica. Ciência e Agrotecnologia, Lavras, v.32, n.2, p.474-480, mar./ abr. 2008
TAIZ, L.; ZEIGER, E. Fisiologia vegetal. Porto Alegre: Artmed, 2004. 719p.

ZAGO, C.P. Utilização do sorgo na alimentação de ruminantes. In: EMPRESA BRASILEIRA DE PESQUISA AGROPECUÁRIA. Manejo cultural do sorgo para forragem. Sete Lagoas, 1992. p.9-26. 